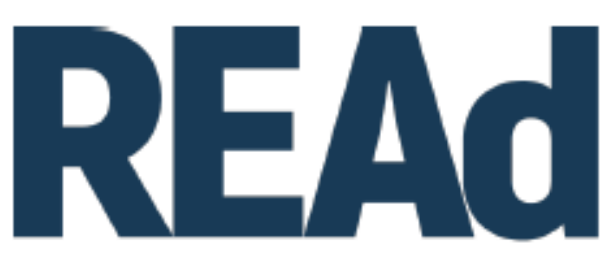

Revista Eletrônica de Administração

\title{
MÉTODOS BIOGRÁFICOS PARA A PESQUISA EM ADMINISTRAÇÃO: PRINCÍPIOS, POTENCIALIDADES, PRÁTICAS E DESAFIOS ${ }^{1}$
}

\author{
Fabiana Pimentel Santos ${ }^{2}$
}

Eduardo Paes Barreto Davel ${ }^{3}$

http://dx.doi.org/10.1590/1413-2311.320.103048

\begin{abstract}
RESUMO
As potencialidades dos métodos biográficos são consideráveis para a Administração, apesar do conhecimento atual sobre esses métodos ainda aparecer disperso e fragmentado quanto às abordagens, definições, conceitos e práticas de uso. O objetivo deste artigo é integrar contribuições de vários campos disciplinares - incluindo a Administração - para sistematizar conhecimentos acerca dos princípios, potencialidades, práticas e desafios dos métodos biográficos. A pesquisa é baseada em uma revisão sistemática das publicações voltadas para os métodos biográficos, a partir de uma inclusão de suas várias terminologias (e.g. história oral, história de vida, autobiografia, narrativa de prática). Os resultados da pesquisa buscam contribuir com o avanço do conhecimento na área de metodologia de pesquisa em Administração, ao integrar, atualizar e discutir conhecimentos sobre os métodos biográficos.
\end{abstract}

Palavras-chave: Método biográfico. Metodologia de pesquisa. Pesquisa qualitativa. Administração.

\section{BIOGRAPHICAL METHODS FOR MANAGEMENT RESEARCH: PRINCIPLES, POTENTIALITIES, PRACTICES AND CHALLENGES}

Biographical method's potential is considerable for the Management, although the current knowledge about this method still appears dispersed and fragmented as to the approaches, definitions, concepts and practices of use. The purpose of this article is to integrate contributions from various disciplinary fields - including Management - to systematize knowledge about

\footnotetext{
${ }^{1}$ Recebido em 16/5/2020, aceito em 13/4/2021.

${ }^{2}$ Universidade Federal da Bahia - Núcleo de Pós-Graduação em Administração; Salvador - BA (Brasil); https://orcid.org/0000-0002-2160-7536; fabianapimentel8@gmail.com.

${ }^{3}$ Universidade Federal da Bahia - Núcleo de Pós-Graduação em Administração; Salvador - BA (Brasil); https://orcid.org/0000-0003-0610-6474; davel.eduardo@ gmail.com.
} 
principles, potentials, practices and challenges of the biographical method. The research is based on a systematic review of publications focused on the biographical method, from an inclusion of its various terminologies (e.g. oral history, life history, autobiography, practice narrative). The research results seek to contribute to the advancement of knowledge in the area of research methodology in Management, by integrating, updating and discussing knowledges about the biographical method.

Keywords: Biographical method. Methodology. Qualitative research. Management.

\section{MÉTODOS BIOGRÁFICOS PARA LA INVESTIGACIÓN DE GESTIÓN: PRINCIPIOS, POTENCIALIDADES, PRÁCTICAS Y DESAFÍOS}

El potencial de los métodos biográficos es considerable para la Administración, aunque el conocimiento actual sobre estos métodos todavía parezca disperso y fragmentado en cuanto a los enfoques, definiciones, conceptos y prácticas de uso. El propósito de este artículo es integrar las contribuciones de varios campos disciplinarios, incluida la Administración, para sistematizar conocimientos sobre los principios, potenciales, las prácticas y los desafíos de los métodos biográficos. La investigación se basa en una revisión sistemática de publicaciones centradas en los métodos biográficos, a partir de la inclusión de sus diversas terminologías (por ejemplo, historia oral, historia de la vida, autobiografía, narrativa práctica). Los resultados de la investigación buscan contribuir al avance del conocimiento en el área de la metodología de investigación en Gestión, integrando, actualizando y discutiendo los conocimientos sobre los métodos

biográficos.

Palabras clave: Método biográfico. Metodología. Investigación cualitativa. Administración.

\section{INTRODUÇÃO}

Biografia, história de vida (LAMBRIGHT; QUINN, 2011), história de vida coletiva (LIEBLICH, 2013), autobiografia (WATSON, 2009), narrativa de prática (ROULEAU, 2015), história oral (ALBERTI, 2005; FERREIRA; AMADO, 2009), história pessoal, autonarrativas, biografia histórica, método biográfico narrativo interpretativo, método narrativo (RIESSMAN, 2008) são apenas algumas das nomenclaturas com as quais o pesquisador pode se deparar ao buscar informações sobre como incluir biografias à metodologia de suas pesquisas. Trata-se de uma diversidade de teorias, conceitos e nomenclaturas oriundos de diferentes disciplinas Antropologia, Sociologia, Psicologia, História, Medicina, Educação, Filosofia, Religião, Ciência Política, Literatura (ROULEAU, 2015; CUNHA et al., 2017; ATIKNSON, 2012). Em respeito e apreço por essa diversidade denominaremos os métodos biográficos sempre no plural.

Dentro dessa diversidade, o ponto focal dos métodos biográficos reside na valorização do sujeito ao priorizar os princípios da oralidade como meio para a compreensão de fenômenos e 
situações a partir da narração de uma trama de acontecimentos vivenciados no passado da pessoa pesquisada. Assim, esses métodos baseiam-se no estudo dos acontecimentos históricos, instituições, grupos sociais, categorias profissionais, momentos, à luz de depoimentos de pessoas que deles participaram por meio do acesso a vivências, memórias e experiências relatadas (CAPPELLE et al., 2010). Ao destacar a voz do entrevistado como contador de história vivida, os métodos biográficos enfatizam os fluxos entre o indivíduo (subjetividade, identidade) e o contexto (histórico, social, organizacional, laboral, familiar, etc.), sendo útil em pesquisas onde esta relação é preponderante.

No campo da Administração, ainda que de forma reduzida, dispersa e fragmentada, a utilização dos métodos biográficos aparece tanto em pesquisas teóricas (CZARNIAWSKA, 2002; HATCH, 1996; MAITLIS, 2012; TSOUKAS; HATCH, 2001; COLOMBY et al., 2016; ICHIKAWA; SANTOS, 2003) quanto em pesquisas empíricas (CUNHA et al., 2017; FÉRMEUX; PAVAGEAU, 2020; WATSON, 2009; ROULEAU, 2015; ROLEAU; BALOGUN, 2011). Suas características favorecem o estudo de temas como estratégia, gestão de carreiras, identidade, liderança, tomada de decisão, mudança organizacional, dentre outros. A reduzida integração de conhecimentos sobre a sua aplicação pode justificar: (a) uma incipiente adoção dos métodos biográficos pelos pesquisadores em Administração e (b) uma fraca robustez dos conhecimentos desenvolvidos pelas raras pesquisas que o adotam.

O objetivo deste artigo é integrar contribuições de vários campos disciplinares - incluindo a Administração - para gerar um conhecimento sistematizado sobre os princípios, potencialidades, práticas e desafios dos métodos biográficos. O estudo foi realizado com base em uma revisão sistemática de produções acadêmicas publicadas (1980-2020) nas bases de dados nacionais e internacionais (SPELL, SCIELO, Sage Publications, Routledge, Periódicos CAPES, Library of Congress, Emerald, Academy of Management). A busca foi feita a partir dos seguintes descritores: "método biográfico", "história de vida", "biografia", "história oral" (nas bases brasileiras) e "biographical method", "life story", "biograph" e "oral history" (nas bases internacionais). A pesquisa selecionou 209 textos (artigos, livros, capítulos de livros, teses e dissertações) que apresentaram relevância dentro dos parâmetros e propósito da pesquisa. O processo de busca e seleção de material relevante foi dinâmico e ocorreu em várias etapas. Em uma primeira etapa de seleção foram verificadas as produções consistentes e coerentes que tratavam teórica ou empiricamente sobre os métodos biográficos. Em uma segunda análise desse material, foram mapeadas suas referências bibliográficas na busca de outras produções relevantes. Essas referências foram pesquisadas, analisadas e integradas ao 
repertório da pesquisa. O processo de revisão ocorreu dentro de uma dinâmica de bola de neve, que chegou a um fim quando nenhuma referência emergia como nova ou relevante.

O processo de análise permitiu constatar a dispersão, reduzida integração e fragmentação dos conhecimentos sobre métodos biográficos da produção acadêmica pesquisada. Diante disso, os resultados da pesquisa repousam sobre a sistematização desses conhecimentos por meio do desenvolvimento de algumas categorias organizadoras: princípios, potencialidades, práticas e desafios. O artigo oferece contribuições para o avanço do conhecimento na área de metodologia de pesquisa em Administração, tanto ao possibilitar uma melhor compreensão teórico-epistemológica sobre os métodos biográficos, quanto ao oferecer orientações para a sua aplicação na prática de pesquisa. Seus resultados auxiliam os pesquisadores deste campo a adotar uma atitude mais consciente e qualificada durante o uso dos métodos biográficos, gerando assim melhores resultados de pesquisa.

Além desta introdução e da conclusão, o artigo se estrutura em quatro seções. Na seção 1, serão apresentados os princípios e potencialidades dos métodos biográficos dentro de um esforço de integração do conhecimento acumulado. Na seção 2, será demonstrado como esses métodos enfocam diferentes temas e podem, efetivamente, contribuir para o avanço do conhecimento na área de Administração. Na seção 3, serão organizadas e apresentadas um conjunto de práticas para ajudar o pesquisador na aplicação dos métodos. Por fim, na seção 4, serão discutidos alguns desafios de uso dos métodos na prática de pesquisa.

\section{PRINCÍPIOS E POTENCIALIDADES DOS MÉTODOS BIOGRÁFICOS}

Enquanto base epistemológica, os métodos biográficos têm raízes na Hermenêutica e na Fenomenologia, vinculando-se ao paradigma interpretativista, que critica modelos positivistas de pesquisa e valoriza as memórias na literatura e na cultura popular, fortalecendo movimentos identitários, promovendo uma cultura terapêutica baseada na história de vida dos pacientes e enfatizando a agência e a subjetividade nos processos sociais. Isso se traduz em uma prática de pesquisa que acolhe a intersubjetividade, rejeita as dicotomias e se abre para a complexidade. Campos como a Psicologia, a Teoria Crítica e a Educação vêm sendo determinantes para a afirmação destes métodos no contexto contemporâneo (MAITLIS, 2002).

Os métodos biográficos estão enraizados em, pelo menos, quatro grandes alicerces nas Ciências Sociais: (a) a história de vida, (b) biografia e autobiografia literárias, (c) biografia e autobiografia sociológica e (d) a história oral. O uso da história de vida como uma fonte de 
pesquisa tem uma longa tradição no campo da Sociologia e está frequentemente associada à Chicago School of Sociology (MERRILL; WEST, 2009; ROBERTS, 2002) cujo compromisso era revelar e interpretar os significados vinculados às interações sociais, bem como compreender a vida dos indivíduos comuns e a variedade cultural de grupos urbanos. A emergência da narrativa no contexto das pesquisas em Ciências Sociais se insere no que se convencionou chamar de "virada biográfica" (MERRILL; WEST, 2009) ou "virada narrativa" (CZARNIAWSKA, 2004; REISSEMAN, 2008). No campo da Sociologia, parte-se da ideia de que os textos são formados dentro de um processo social. Por isso, as biografias e autobiografias não somente ajudam a compreender a vida do indivíduo, mas também sua produção no âmbito social, destacando a interação da dimensão individual e social (ROBERTS, 2002). Para a Antropologia, a oralidade é central nas pesquisas sobre a transmissão de tradições, principalmente no caso de sociedades tradicionais ou rurais (LOZANO, 2009; ALBERTI, 2000).

No campo dos estudos literários, o uso do método biográfico se caracteriza pelo fato de que o estudo da vida de um indivíduo é em si o fenômeno pesquisado. O foco recai nas especificidades e características de indivíduos e grupos estudados, sendo secundário o contexto social em que estão situados. Essa característica diferencia o uso das narrativas nesses campos do conhecimento se comparado a seu uso em tradições como a da História ou da Sociologia, por exemplo. No campo da História, a valorização das fontes orais começa apenas na década de 1940 com o advento tecnológico que possibilitava a gravação e a reprodução de entrevistas, ganhando vulto entre as décadas de 1960 e 1970, com a emergência das lutas pelos direitos civis. A partir de então, a história oral passa a ser vista como uma forma de dar voz às minorias, fontes até então relegadas, para favorecer a construção de uma contra história que se colocava diante das versões consagradas, valorizando-se o papel do sujeito na história (ROBERTS, 2002).

Cunha et al. (2017) destacam que os princípios centrais dos métodos biográficos são a narrativa, a oralidade, o holismo, o construtivismo, a relevância contextual, o caráter situacional, a ênfase relacional, o potencial autorreflexivo e a sensibilidade a contradições. Integrando suas categorias com contribuições de outras referências analisadas, oferece-se a seguir um aprofundamento da compreensão de tais princípios.

Princípio da narrativa. Os métodos biográficos se apoiam em experiências que podem ser convertidas em narrativas. $\mathrm{O}$ ato de contar e ouvir histórias é indissociável da experiência humana. A narrativa ganha características, suportes e funções cada vez mais elaborados ao 
longo dos tempos e espaços (e.g. mitos, lendas, fábulas, contos, romances, causos, fofocas, relatos históricos, pinturas, cinema, teatro, ópera, quadrinhos, fotos ou pinturas). A produção e decodificação de narrativas articulam memória e imaginação, faculdades humanas essenciais para a compreensão do mundo e para conectar a dimensão individual à dimensão coletiva e vice-versa.

Ao contar uma história, o narrador conecta eventos em uma dada sequência, envolvendo personagens específicos e particularidades de um dado cenário (RIESSMAN, 2008). Constituem um sequenciamento de ações (o que), executadas por alguém (quem), em um determinado lugar ou contexto (onde), durante um dado espaço de tempo (quando). Ação e temporalidade são, portanto, elementos básicos e estão imbricados por meios da sequencialidade ou encadeamento, ideias fundamentais para a compreensão deste conceito. Entretanto, esta temporalidade pode partir tanto de uma concepção ocidental, tributária das proposições aristotélicas (começo, desenvolvimento e desfecho), quanto de uma concepção oriental, na qual a experiência temporal é mais circular, sobreposta ou não linear. Narrativas são modos de conhecimento e de comunicação (CZARNIAWSKA, 2004) que podem tanto ter como ênfase as ações e seus impactos, quanto as emoções (CUNHA et al., 2017).

As histórias são construídas para dotar a experiência humana de sentido; são uma forma de organização da experiência humana (MUSSON, 1998). Narrar e organizar são conceitos intrinsecamente ligados e centrais no uso dos métodos biográficos no estudo das organizações. A organização pode ser vista como um "sistema coletivo de narrativas", no qual a atuação narrativa é primordial para a construção de sentido entre seus membros e na correlação entre memoria individual e institucional (BOJE, 1991).

Princípio da oralidade. Embora não seja o único, a entrevista é a principal técnica de coleta de dados dos métodos biográficos, o que coloca ênfase na oralidade. A fala e a enunciação das histórias pressupõem práticas como a de uma conversa cotidiana. Nessa conversa, uma história leva a outra, tópicos são mudados repentinamente, memórias são acessadas, correlações são feitas, idas e vindas afetam a cronologia dos fatos e temas aparentemente desconexos são associados (REISSMAN, 2008). Desse modo, a oralidade dos métodos biográficos favorece o acesso a uma riqueza de detalhes, relações contextuais e processos de construção de sentido muito significativas ao estudo de fenômenos complexos e relacionados à subjetividade e à intersubjetividade.

Princípio do holismo. Os métodos biográficos propiciam uma visão holística sobre comportamentos, relacionamentos, pensamentos e emoções. Eles permitem uma visão mais 
integrada de informações oriundas de múltiplos informantes que possuem lentes variadas e diferentes pontos de vista ao longo do tempo. Assim, demonstram como vários elementos evoluem ao longo do tempo, sofrendo a influência de múltiplos contextos, como o pessoal, familiar, econômico, tecnológico e político (CUNHA et al., 2017).

O princípio do construtivismo. Os métodos biográficos são construtivistas, porque se relacionam com aspectos interpretativos e com a construção de sentido, enfatizando o que os indivíduos criam a partir de suas experiências. Seu foco não está na precisão factual da história construída, mas no significado que tem para o entrevistado. A história é uma composição de significados interpretados e autorrepresentações (CUNHA et al., 2017). Toda leitura é uma interpretação e toda interpretação é uma associação que amarra o texto interpretado a outros textos, outras vozes (CZARNIAWSKA, 2002). A construção de sentido se apresenta tanto no ato de narrar quanto no ato de interpretar essas narrativas (LEVI, 2009).

O princípio do contexto. Nas biografias, as informações são altamente sensíveis ao contexto, pois as histórias dos indivíduos estão situadas nas circunstâncias de sua vida (CUNHA et al., 2017). A própria raiz sociológica dos métodos biográficos reforça essa característica. A história de vida dos indivíduos é entendida não apenas em termos da sua singularidade e individualidade, mas principalmente por sua relação com o contexto. As narrativas deixam aparentes a relação entre o indivíduo e a sociedade, expondo como, em situações específicas e na perspectiva dos indivíduos e grupos, percepções gerais e modos de pensar são representados e monitorados (ROBERTS, 2002).

O princípio da situação. Nos métodos biográficos, os relatos demonstram como as atitudes, emoções e interpretações são dinâmicas e mudam com o passar do tempo (CUNHA et al., 2017), ou seja, são dinâmicas sempre situadas. O caráter temporal de uma história dá conta de um momento específico em que ações, emoções e interpretações acerca delas aconteceu. Os relatos podem tanto percorrer o tempo, considerando transformações ocorridas em seu transcurso, quanto no ato de contar a história novas relações e sentidos podem se apresentar, reconfigurando interpretações naquele instante. Esse dinamismo relacionado à inerente temporalidade das histórias dota a pesquisa da capacidade de acessar informações processuais sobre, por exemplo, processos de mudança, tomadas de decisão, liderança.

O princípio da relação. Compreender uma história de vida requer do pesquisador colocar as relações humanas no centro do processo. Histórias são testemunhos das relações vivencias por um indivíduo e seus reflexos. Os métodos biográficos retratam a relação dos indivíduos com o ambiente e as conexões humanas que definem a vida de alguém. Mesmo as 
narrativas mais pessoais e psicológicas estão em estreita relação com o significado coletivo, como suposições, regras sociais, convenções e similares. Ou seja, a narrativa enquadra as ações dos indivíduos na articulação de um contexto social relacional (CUNHA et al., 2017). Além disso, o próprio ato de contar uma história é um ato relacional, tendo em vista que aquele que narra sua história de vida sempre a narra para alguém. A narrativa está dotada de um caráter intencionalmente comunicativo e heurístico que a transforma em uma interação social completa (BUENO, 2012).

O princípio da autorreflexão. Os métodos biográficos possibilitam ao entrevistado refletir sobre sua história à medida que ele realiza seu relato. $\mathrm{O}$ ato de narrar sua história situa o entrevistado em uma espécie de divã, o convidando a refletir sobre seu eu interior, seus dilemas e incertezas, motivações, decisões, escolhas a fim de melhor informar sua experiência (CUNHA et al., 2017). Isso dota os métodos biográficos com a capacidade de se acercar a fenômenos complexos que envolvem tomada de decisão e motivações, oferecendo um acesso privilegiado a processos subjetivos. Possibilita também que o processo de pesquisa enriqueça a experiência do entrevistado, devolvendo a este um potencial benefício em se engajar com a pesquisa.

O princípio da sensibilidade à contradição. Devido aos princípios da relação, do contexto e da autorreflexão, os métodos biográficos se tornam sensíveis a contradições, visto que evidenciam a complexidade das experiências vividas e seus paradoxos (CUNHA et al., 2017). Longe de uma trajetória linear e unidirecional, uma história ganha muitas vezes um sentido construído no próprio ato de contação. Essa ilusão biográfica (BOURDIEU, 2009) esconde diversas bifurcações, contradições, conflitos internos e situações paradoxais que marcam a vida de qualquer indivíduo. Ao expor essa ilusão, os métodos biográficos guardam um potencial muito grande de investigação de motivações subjacentes e dilemas vivenciados em situações de conflito e mudança, expondo não apenas sua resolução, mas também o processo percorrido para tal.

As potencialidades dos métodos biográficos são variadas, apesar de destacarmos pelos menos três. A primeira potencialidade refere-se à valorização do indivíduo na construção da história organizacional, mantendo-se sempre seu vínculo com a dimensão coletiva. A principal potencialidade dos métodos biográficos é valorizar o papel do sujeito na história, possibilitando uma melhor compreensão da construção das estratégias de ação, da construção de sentidos e das representações de grupos e indivíduos em um dado contexto social. Ao considerarem a relação entre a dimensão individual e coletiva, os métodos biográficos 
permitem compreender a dimensão subjetiva dos atores sociais possibilitando que a história de um indivíduo reflita um momento histórico e revelando os valores da sociedade que podem interferir na realidade organizacional (MAGESTE; LOPES, 2007). Nas ciências sociais, os métodos biográficos são reconhecidos por sua capacidade de dar voz às pessoas (por exemplo, imigrantes, agricultores, comerciantes e outros) que geralmente são excluídas da história oficial, via de regra interpretada em favor da interesses das classes dominantes. Desse modo, apresentam um caráter emancipatório por meio recuperação da própria história por parte do pesquisado, o que se mostra relevante na construção de identidades e na compreensão de processos antes velados, reprimidos ou automatizados (FRANÇOIS, 2009).

Da mesma maneira, no estudo das organizações, as narrativas permitem dar voz não apenas aos gerentes médios e inferiores, mas também a todos os atores pertencentes aos vários subgrupos dentro da organização ou em torno da organização que geralmente não são considerados nas pesquisas desenvolvidos por meio de outros métodos (DENIS; LANGLEY; ROULEAU, 2010). Isso potencializa o estudo dos fenômenos organizacionais em multinível, nos permitindo melhor entender as práticas e habilidades individuais utilizadas nestes processos. Também permite capturar rotinas, eventos, interações e conhecimentos que constituem as práticas dos gestores, alcançando melhor o nível micro organizacional (ROULEAU, 2015).

A segunda potencialidade dos métodos biográficos consiste na intensificação da reflexividade na pesquisa. Assim, somos conduzidos a converter o próprio processo de pesquisa em uma ferramenta de construção de sentido (de si e do mundo) por meio do acesso privilegiado às experiências. Colomby et al. (2016) recorrem ao conceito de "experiência da reflexão" para destacar a capacidade dos métodos biográficos em gerar no entrevistado sentidos para suas próprias vivências em processo de aprendizado. Ao reposicionar a interação pesquisado-pesquisador, métodos biográficos abrem novas portas para a pesquisa, levando em conta que as histórias de vida não são algo fixo nem estático. Pelo contrário, seus sentidos se formam na relação entre o indivíduo e seu contexto.

A terceira potencialidade dos métodos biográficos refere-se a facilitar o acesso a informações complexas, contextualizadas, situadas, sutis e sensíveis. Os métodos são particularmente adequados para explorar problemas e questões para as quais as informações são de difícil acesso (ROULEAU, 2015). Ao incorporarem a subjetividade e a intersubjetividade como parte inerente do processo de pesquisa, os métodos biográficos possibilitam a investigação dos fenômenos complexos, alcançando dimensões mais sutis, sem 
reducionismos e sem uma interpretação linear entre causa e efeito (LIČEN; CIUHA, 2012). Consequentemente, permitem a coleta de informações complexas o que maximiza o tempo e os recursos dos pesquisadores. Ao fomentar a reflexão da vida por meio de narrativas, os métodos contribuem para que o pesquisador alcance uma interpretação complexa das organizações (TSOUKAS; HATCH, 2001), tomando o próprio fenômeno organizacional como uma narrativa por se tratar de uma sucessão de acontecimentos transcorridos em uma dimensão temporal. Esses acontecimentos são imersos em um dado contexto, perpassados por relações dinâmicas e paradoxais, que agregam diversas subjetividades e cujo sentido é construído durante e a partir do próprio processo de ação-reflexão, no qual se insere também o próprio esforço do pesquisador.

Em suma, princípios e potencialidades são inseparáveis de tradições epistemologias e teóricas às quais os métodos biográficos se vinculam. No processo de adoção e aplicação dos métodos biográficos, tanto princípios e potencialidades devem ser considerados, reflexivamente, mas também suas conexões epistemológicas e teóricas. Dessa forma, a prática metodológica pode ganhar reflexividade e melhor consistência em suas aplicações na área de Administração. Apesar dos métodos biográficos ainda aparecem de forma tímida na pesquisa em Administração, suas aplicações já expressam força e relevância em diversos temas e enfoques. Ao percebermos que existem pesquisas robustas e relevantes, em Administração, que se pautaram pelos métodos biográficos, esses exemplos ajudam a legitimar o trilhar de pesquisas futuras.

\section{MÉTODOS BIOGRÁFICOS COMO MEIO DE AVANÇO DO CONHECIMENTO EM ADMINISTRAÇÃO}

$\mathrm{Na}$ área da Administração, os métodos biográficos orientam pesquisas com diversas temáticas tais como: estratégia organizacional (ROULEAU; BALOGUN, 2011; ROULEAU, 2015), identidade organizacional (CZARNIAWSKA, 1997), identidade de trabalho (WATSON, 2009), liderança (FRÉMEUX; PAVAGEAU, 2020; CUNHA; LEWIS, 2017), relações de gênero (CAPPELLE et al., 2010), assédio moral (CORRÊA; CARRIERI, 2007) e instituição total (CARVALHO; FISCHER, 2006). Contudo, a análise sistemática realizada possibilitou identificar uma incipiente adoção dos métodos biográficos pelos pesquisadores em Administração, sobretudo no contexto brasileiro. Além disso, por vezes, verificou-se a fraca robustez dos conhecimentos desenvolvidos por parte das pesquisas que o adotam. 
Tal situação é muitas vezes utilizada para descredibilizar equivocadamente a validade dos métodos biográficos, associando-os a práticas pouco apuradas de pesquisa e a resultados excessivamente impressionistas. A presente pesquisa considera que, longe disso, pesquisas biográficas podem contribuir de forma significativa e relevante para o avanço do conhecimento em Administração desde que adotadas com consciência crítica acerca de seus princípios teóricoepistemológicos e aplicadas competentemente no que concerne aos procedimentos metodológicos e analíticos que lhes correspondem.

Nesse sentido, essa seção busca desmistificar a ideia dos métodos biográficos como periféricos e favorecer um entendimento de seu pleno potencial na pesquisa em Administração. Para tanto, o que se segue é a ilustração da sua aplicabilidade por meios de cinco pesquisas publicadas em revistas científicas reconhecidas pela sua excelência acadêmica. A escolha dessas pesquisas deveu-se ao detalhamento dos procedimentos metodológicos apresentados e à densidade conceitual das contribuições alcançadas. Além disso, deveu-se também à centralidade e contemporaneidade dos campos do conhecimento em Administração a que se dedicam: estratégia, identidade e liderança.

\subsection{MÉTODOS BIOGRÁFICOS NA PESQUISA SOBRE ESTRATÉGIA}

No campo das pesquisas sobre estratégia, Roleau e Balogun (2011) baseiam-se nas narrativas de prática: histórias de vida com foco nas experiências profissionais dos entrevistados. O objetivo da pesquisa é entender o papel dos gerentes intermediários na implementação de estratégias de mudança organizacional. Como os gestores intermediários faziam a ponte entre as estratégias definidas pelas instâncias superiores e suas equipes? Os gerentes médios entrevistados foram convidados a narrar sua trajetória profissional com ênfase particular na reestruturação organizacional que acabavam de experimentar, sendo encorajados a reunir ações, crenças e sentidos que os ajudava a dar sentido ao processo que estavam vivenciando. Também foram providos grupos interativos de discussão nos quais os gestores compartilhavam os valores, as atitudes e representações envolvidos no processo.

Nesta pesquisa, quatro histórias foram selecionadas como as mais ricas e representativas: dois gerentes de uma empresa de comunicação e dois gerentes de uma multinacional de engenharia. As pesquisadoras concluíram que duas atividades narrativas foram adotadas pelos gerentes intermediários (em processos de reestruturação organizacional) como forma de praticar as estratégias definidas pela organização e assim engajar e motivar suas equipes. A 
primeira atividade é a "performance da conversa", que diz respeito a construir um discurso com palavras, símbolos e metáforas, deliberadamente escolhidos para possibilitar a construção de sentido para o processo que estava em curso. A segunda atividade é a 'montagem da cena', identificando e atraindo pessoas das equipes que eram capazes de formar uma rede de influência e reverberação para a construção de sentido que estava sendo criada. A principal contribuição dos métodos biográficos na pesquisa de Roleau e Balogun (2011) foi permitir explorar o papel das competências discursivas na construção de sentidos que deem lastro ao processo de mudança organizacional. O uso dos métodos biográficos se mostrou poderoso por possibilitar a compreensão de como processos subjetivos se articulam com a dimensão coletiva dentro de uma organização.

Outra pesquisa que mobilizou os métodos biográficos de forma distintiva é Rouleau (2015). O objetivo é entender o papel dos gerentes intermediários em processos de reestruturação organizacional com foco na análise da estratégia como prática. A coleta de informações foi baseada na "opinião especializada", recorrendo a contatos pessoais e uma empresa especializada em gestão de carreiras para selecionar os gestores que comporiam seu grupo de pessoas a serem pesquisadas. Além disso, foi solicitado a cada participante que indicasse outro gerente intermediário que tivesse passado por um processo de reestruturação organizacional. Desse modo, 58 narrativas de prática foram coletadas, com base em três entrevistas, no mínimo, por entrevistado.

Os entrevistados conheciam previamente o propósito da entrevista e podiam pensar sobre o que relatar durante a entrevista. No primeiro encontro de entrevista, eles eram convidados a narrar sua trajetória profissional do período escolar, passando por sua primeira experiência de gerenciamento e chegando até quando foi recrutado para o trabalho em que se encontrava naquele momento. $\mathrm{O}$ encontro os ajudava a lembrar como eles se tornaram gerentes intermediários e quais foram as experiências mais importantes neste processo. $\mathrm{O}$ segundo encontro de entrevista era voltado para experiência presente. Conversava-se sobre o papel que desempenharam no processo de reestruturação e nos sentidos que criaram a partir do processo vivenciado. O terceiro encontro de entrevista tratou principalmente de sua previsão de carreira, envolvendo seu próprio futuro e o futuro da empresa após a reestruturação.

Diante da massiva quantidade de informações coletadas (aproximadamente 300 horas de entrevistas), a pesquisadora transcreveu apenas as 15 narrativas de prática que traziam informações mais relevantes. A análise foi realizada em duas etapas: (a) codificação das informações com base em fatos e categorias relevantes para o narrador e (b) análise extensiva 
das narrativas de práticas. Por meio dessa estratégia de análise, foi possível identificar 4 conjuntos de práticas que os gerentes usam para lidar com uma reestruturação, cada uma delas fundamentada em um tipo específico de conhecimento. Essas práticas são ilustradas por meio do exemplo de Mary, uma enfermeira que trabalhava há 25 anos no mesmo centro de saúde e que mudou de cargo com a reestruturação que a organização sofreu. Assim, Rouleau (2015) apresenta cada conjunto de práticas: (a) considerar a reestruturação como mais crise da vida, (b) convencer os outros, (c) mobilizar redes e (d) lidar com imprevistos.

\subsection{MÉTODOS BIOGRÁFICOS NA PESQUISA SOBRE IDENTIDADE}

Com o propósito de correlacionar narrativa, identidade laboral e construção social, Watson (2009) analisa a autobiografia que Leonard Hilton, gerente sênior em uma empresa de telecomunicações. A autobiografia foi escrita após a aposentadoria para oferecer um legado de memória para seu filho. Apesar da entrevista biográfica ser a via privilegiada de coleta de informações nos métodos biográficos, outras técnicas de coleta e outras fontes de informações também podem ser acionadas. Watson (2009) justifica a escolha da autobiografia de Hilton como um estudo de caso não por ele ser um gerente típico ou um relator de história de vida. A escolha se dá por ele ser um "caso extremo" de relação identidade-trabalho, com em alguém que demonstra um pensamento narrativo e avançadas habilidade para narrar. Assim, o caso foi escolhido como adequado na buscar ideias sobre o papel das narrativas na construção da identidade laboral.

Durante a análise, foram adotados dois procedimentos: (a) uma leitura cuidadosa ao longo de dois meses e a extração de uma versão muito mais condensada (durante esse processo, foram listados temas e categorias que pareceram teoricamente relevantes para o objetivo da pesquisa) e (b) o material foi reorganizado com base nesta seleção de temas e categorias e posteriormente lido e relido à luz da literatura acadêmica para produzir as conceituações e análises apresentadas na pesquisa. Apoiando suas conclusões com trechos da narração de Hilton, o pesquisador apresenta suas contribuições conceituais para o avanço do campo de pesquisa sobre trabalho e identidade: (a) longe de uma construção individual, a identidade se constrói em um trânsito permanente entre a agência individual e o contexto sociocultural em que o indivíduo está inserido, (b) a construção da identidade laboral está em permanente trânsito com a construção identitária do sujeito numa perspectiva mais ampla. Assim, a pesquisa ilustra a natureza dual e complexa da identidade e apresenta como as narrativas são capazes de dar acesso a esses 
processos sem privilegiar um ou outro polo isoladamente. Elas trazem em si, amalgamadas, essas duas dimensões indissociáveis: o dentro (a ação) e o fora (o contexto da ação).

\subsection{MÉTODOS BIOGRÁFICOS NA PESQUISA SOBRE LIDERANÇA}

Frémeux e Pavageau (2020) investigam a relação entre liderança e trabalho significativo. O objetivo é identificar que dimensões são consideradas pelos líderes com vistas a adotar práticas de liderança que contribuem para trabalho significativo. Foram feitas 42 entrevistas com participantes selecionados em oito programas de desenvolvimento de liderança oferecidos por empresas de coach. Os entrevistados eram um misto de profissionais que efetivamente atuavam em posições de lideranças e que almejavam ocupar essa posição. O principal critério de seleção dos entrevistados é que todos deviam ser membros de comitês executivos e participar da esfera estratégica da organização em que trabalhavam. As entrevistas foram gravadas, transcritas e verificadas, buscando uma descrição precisa da resposta dos entrevistados. As entrevistas foram divididas em duas fases de pesquisa: exploratória (15 entrevistas exploratórias, com duração entre 30 e 60 minutos) e biográfica (27 entrevistas biográficas, com duração de aproximadamente 105 minutos).

$\mathrm{Na}$ fase exploratória, foram feitas perguntas mais genéricas sobre o papel dos líderes e sobre as atividades desempenhadas e, desde já, se revelou a importância da questão do significado dado pelos líderes à sua atividade profissional. Nesse estágio, foram identificadas as três principais categorias de significado relacionados aos líderes, aos seus relacionamentos com colegas de trabalho e com a dimensão social do seu trabalho. Nesse estágio, os pesquisadores perceberam como o uso da história de vida poderia desdobrar essas categorias para subcategorias e elucidar sua dinâmica, tendo em vista que as histórias são verdadeiros repositórios de sentidos.

$\mathrm{Na}$ fase biográfica, o número de entrevistas realizadas foi definido pelo princípio da saturação. Quando as informações passaram a se mostrar redundantes o processo de coleta foi concluído. Durante essa fase, os pesquisadores focaram mais no conceito de liderança significativa sem referência a conceitos oriundos da teoria. Era feita uma pergunta aberta: que significado você dá a seu trabalho como líder? Dispunham de outras perguntas para orientar os estimular o rumo do relato, se fosse necessário: “Que experiências impactaram sua atividade como líder?", “Como você se descreve como líder?’, "Você poderia dar algum exemplo de projetos e práticas como líder?’'. 
$\mathrm{Na}$ análise das informações, foi gerada uma lista com categorias mencionadas pelos líderes que posteriormente foi refinada, unificando ou separando categorias para evitar sombreamentos ou redundâncias. Essa categorização refinada foi correlacionada pelos pesquisadores com as categorias da base teórica adotada na pesquisa. Do processo, emergiram seis novas dimensões de significado que os líderes dão a sua atividade: exemplo moral, autoconsciência, apoio pessoal e profissional, espírito comunitário, compromisso de trabalho compartilhado e atitude positiva em relação aos outros e eventos.

Outra pesquisa sobre liderança com base nos métodos biográficos é pesquisa realizada por Cunha et al. (2017). Para defender o entendimento da liderança como processo, os pesquisadores buscaram avaliar como eventos da infância afetam o processo de liderança, mais especificamente, como relações parentais tensas na primeira infância influenciam os líderes. Nesse contexto, os métodos biográficos oferecem uma visão mais rica em nuances do processo de liderança, ao trazer à tona em forma de narrativas aspectos como a autorreflexão, a construção de sentido e o enfrentamento de situações paradoxais inerentes ao cotidiano dos líderes. As informações analisadas são oriundas da história de vida de três líderes do segmento de tecnologia, coletadas a partir de biografias escritas sobre os líderes e, de forma suplementar, a partir de relatos de parentes e colegas de trabalho, bem como cartas e reportagens veiculadas na imprensa. As biografias foram utilizadas para obter categorias comuns, bem como diferenças.

$\mathrm{Na}$ análise, as biografias foram organizadas cronologicamente, nas quais foram identificados (a) temas centrais em diferentes esferas (infância, desenvolvimento, origens como empreendedor e estilos de liderança) e (b) quatro padrões (os líderes eram visionários, tinham um temperamento corrosivo, eram narcisistas e foram adotados). Em uma etapa mais profunda de análise, foi possível identificar inconsistências nas narrativas analisadas. Essas contradições pareceram úteis aos pesquisadores para explorar como os líderes podem ser amados e odiados simultaneamente, bem como uma mesma característica pode ser o principal ponto forte e fraco dos líderes. A pesquisa de Cunha et al. (2017) destaca o potencial das narrativas em revelar camadas subjacentes e de difícil acesso para outros métodos de pesquisa, tal como os paradoxos e contradições relacionadas aos fenômenos analisados.

\section{MÉTODOS BIOGRÁfICOS NA PRÁTICA DE PESQUISA EM ADMINISTRAÇÃo}


A partir da conscientização do pesquisador em relação aos princípios e principais potencialidades dos métodos biográficos (seção 1) e da exemplificação da sua aplicação no campo da Administração (seção 2), propomos agora oferecer aos pesquisadores a sistematização de conhecimentos que lhes permitam pensar a sua própria prática de pesquisa com vista a torná-la mais fundamentada, consciente e coerente. Cabe destacar que o propósito não é fazer prescrições à guisa de um manual, tendo em vista que a própria natureza construtivista dos métodos biográficos desaconselha este tipo de abordagem. $\mathrm{O}$ foco recai, consequentemente, na sistematização de um conteúdo que apareceu bastante fragmentado e disperso no levantamento bibliográfico realizado, com o intuito de oferecer aos pesquisadores em Administração um panorama geral que lhes sirva de estímulo a considerar e aplicar os métodos biográficos em suas pesquisas futuras.

\section{1 ÂMBITOS}

Em algumas pesquisas, pode-se apresentar como relevante definir de forma mais clara que âmbito os métodos biográficos tomarão no contexto de pesquisa. $\mathrm{O}$ âmbito pode variar em função das particularidades dos estudos desenvolvidos, bem como das disciplinas e tradições teóricas às quais os estudos se vinculam (ROBERTS, 2002). Proposto pela História Oral (FERREIRA; AMADO, 2009), os métodos biográficos podem ter três níveis de mobilização na pesquisa, indo do mais amplo ao mais pontual: (a) disciplina (método como campo do conhecimento, com objetivo próprio e capacidade de gerar produções teóricas para as questões surgidas na prática), (b) metodologia (método como conjunto de procedimentos e preceitos que estruturam e guiam a realização da pesquisa) e (c) técnica (método como técnicas de coleta, transcrição e análise de narrativas). Tal escolha se relaciona com a relevância dos princípios do método para o desenvolvimento da pesquisa em questão. Além disso, implica em um maior ou menor comprometimento do pesquisador no seu domínio de seus conceitos e práticas.

Em relação à mobilização de narrativas na pesquisa biográfica, três modalidades se destacam (BOM MEIHY, 1996): a narrativa como foco (a vida do sujeito entrevistado se constitui em elemento fundamental para o desenvolvimento da pesquisa), (b) o tema como foco (busca-se a narrativa do entrevistado a partir de um assunto específico preestabelecido e a história de vida volta-se para informar a temática central da pesquisa) e (c) a construção social como foco (enfatiza-se a dimensão mais coletiva que individual, em que a história de vida tem como foco de reconstrução de mitos, tradições ou uma visão de mundo mais comunitária). Tais 
opções relacionam-se com a disciplina na qual a pesquisa se desenvolve, bem como com seu objeto.

\subsection{PROCEDIMENTOS TÉCNICOS DE INTERAÇÃO COM O MATERIAL EMPÍRICO: A ENTREVISTA BIOGRÁFICA}

Em pesquisas biográficas, a entrevista é um procedimento central. Todavia, é possível utilizar os métodos biográficos sem entrevistas e/ou com combinações de outras fontes, como a observação, documentos (KIM, 2016) e artefatos pessoais, como diários, cartas, fotografias, perfis, currículos, cartões postais, cartões de aniversário, joias, etc. (ROBERTS, 2002). Na entrevista biográfica, o entrevistado conta nas suas próprias palavras suas experiências (ROULEAU, 2015). Ele escolhe contar sobre sua vida vivida, de acordo com o que se lembra e deseja contar, produzindo uma narrativa sobre o conjunto de sua experiência de vida, em que seus aspectos mais significativos são destacados (ATKINSON, 1998). O propósito do entrevistador é ganhar conhecimentos sobre a experiência do entrevistado por meio de uma reflexão cronológica (CASSELL et al., 2018), capturando a sequência de acontecimentos relatados pelo pesquisado.

A entrevista biográfica pressupõe a articulação entre, no mínimo, um entrevistador e um entrevistado, a partir de um processo duplamente interpretativo que explora a construção de sentidos tanto por parte do entrevistado (ao relatar suas experiências de vida e memórias), quanto por parte do entrevistador, ao analisar tais informações com vistas a alcançar seu objetivo de pesquisa. Não existe uma fronteira nítida e definitiva que distingue entrevistas de forma geral da entrevista biográfica, uma vez que todos tipos de entrevista compartilham muitos traços em comum. Podemos entender a entrevista biográfica como uma entrevista que busca maior detalhamento, melhor descrição e forte enraizamento com a história vivida pelo entrevistado(a). Ou seja, a entrevista biográfica demanda maior densidade de acordo com a temporalidade e espacialidade situadas na história de vida do entrevistado(a). Neste item, vamos privilegiar as pesquisas sobre entrevista no contexto específico dos métodos biográficos.

\subsubsection{Planejamento}

Quatro aspectos devem ser levados em consideração no planejamento de uma pesquisa biográfica: compreender o papel do entrevistador, definir a estruturação da entrevista, 
selecionar os entrevistados e atentar para as questões éticas. Quanto ao papel do pesquisador, é importante partir da compreensão da entrevista biográfica como um espaço transicional dentro do qual ocorrem processos de autonegociação, nos quais podem surgir posturas previsíveis que refletem ideologias dominantes, mas que podem vir a ser questionadas dentro do próprio processo de pesquisa. Isto pode ocorrer quando as pessoas se sentem incentivadas a contar suas histórias e realmente se ouvem (MERRILL; WEST, 2009). A entrevista deve ser vista como um processo ativo ao qual é inerente um caráter interpessoal, pois no processo de entrevista, os participantes estão em constante desenvolvimento. O próprio entrevistador não é estático ou predefinido, como uma fonte de informação a ser acessada. Pelo contrário, ele é construído em relação às contingências comunicativas em andamento durante a entrevista (HOLSTEIN, 1995).

Assim, o processo de pesquisa passa de uma subjetividade passiva - que considera o entrevistado como um repositório de dados que deverão ser extraídos pelo pesquisador tal qual já existem - para uma subjetividade ativa - que considera o entrevistado como uma fonte animada e produtiva de conhecimento narrativo (GUBRIUM; HOLSTEIN, 2012). O pesquisador precisa atentar para a natureza discursiva do processo de entrevista, no qual entrevistador e entrevistado, através de repetidas reformulações de perguntas e respostas, se esforçam para chegar juntos a significados que ambos possam entender, num processo de construção conjunta de sentido (MISHLER, 1986).

Quanto à estruturação da entrevista, é importante considerar abordagem e o formato de entrevista a serem adotados, bem como planejar a duração dos encontros e as questões de pesquisa. A abordagem diz respeito a como serão organizadas as entrevistas. Uma abordagem possível é fornecer ao entrevistado uma lista com tópicos a serem abordados, o que pode ajudar o entrevistado a ter uma melhor noção do terreno a ser coberto e a fortalecer a confiança (MERRILL; WEST, 2009). Outra abordagem é conduzir a entrevista de forma mais interativa, estabelecendo uma conversa com o entrevistado (RIESSMAN, 2008).

É corriqueiro organizar as entrevistas biográficas em diversos encontros. Alguns autores propõem, no mínimo, três encontros. Num primeiro, o entrevistador apresenta o objetivo do estudo e começa com uma pergunta única e aberta, estimulando o entrevistado a contar sua história de vida. No segundo encontro, depois uma análise da entrevista do primeiro encontro, o pesquisador pode apresentar questões mais estruturadas, moldadas pelos interesses teóricos da pesquisa. No terceiro encontro as narrativas coletadas nos encontros anteriores podem alimentar uma entrevista ainda mais focada (MERRILL; WEST, 2009). Outra proposta é que 
no primeiro encontro, o entrevistador parta de uma pergunta base e sem fazer interrupções, deixando o entrevistado ir até não ter mais nada a dizer. Imediatamente depois, ou o mais breve possível, se seguiria o segundo encontro no qual o entrevistador deveria ater-se apenas aos tópicos levantados na narração inicial, seguindo estritamente a ordem em que foram levantadas e usando as palavras do entrevistado na busca de aprofundamento do relato. $\mathrm{O}$ terceiro encontro só poderia ser realizado após concluída a análise preliminar do material coletado nos dois encontros anteriores. Esse encontro seria livremente conduzido à luz do objetivo de pesquisa e de questões teóricas, sem se restringir ao que foi relatado pelo entrevistado (WENGRAF, 2001).

Existem propostas que englobam apenas dois encontros. No primeiro, fase de narração, o entrevistador restringe suas intervenções ao mínimo enquanto o entrevistado narra completamente os eventos e experiências de sua própria vida. Essa narrativa não é interrompida por perguntas, mas pode ser incentivada por expressões não-verbais de interesse e atenção. A ideia é deixar a entrevista seguir seu curso naturalmente para abarcar tudo o que o entrevistado deseja cobrir de sua vida. No encontro de narração, o principal papel do pesquisador é o de um ouvinte e observador. No segundo encontro, fase de conversação, passa-se a um processo de entrevista detalhado composto por perguntas e respostas. O pesquisador passa a exercer um papel ativo de co-construtor. Nesse encontro, a entrevista ganha um caráter discursivo ou dialógico e envolve a criação de significado (KIM, 2006).

Sobre a duração das entrevistas, comumente a duração é de uma hora a uma hora e meia por encontro, por se tratar de uma duração que ajuda o gerenciamento da quantidade de informações a serem relatadas e analisadas (ATKINSON, 2002). Contudo, a duração da entrevista pode ser muito variável a depender do caráter e das circunstâncias da pesquisa.

Sobre as questões da entrevista, a liberdade narrativa do entrevistado é uma questão central. Todavia, para manter o foco da pesquisa, é possível elaborar perguntas antecipadamente, mantendo-se flexível durante o processo de entrevista. As perguntas mais úteis são as abertas, descritivas, estruturais e de contraste. Construções como "como você descreveria", "em que essa situação difere das outras", "qual foi o momento mais memorável” são exemplos de perguntas com potencial de acessar o nível emocional do entrevistado, porque incentivam respostas mais ponderadas e pessoalmente significativas. Outra possibilidade é perguntar a partir de uma sentença explicativa, com a finalidade de contextualizar o entrevistado (KIM, 2016).

É importante que o pesquisador leve em consideração e planeje a adequação da abordagem adotada, o formato de entrevista, as questões apresentadas e a duração dos 
encontros. A necessidade de diversos encontros de entrevistas pode ser inviável para alguns perfis de entrevistados. Por outro lado, uma pergunta inicial pode ser ameaçadora para pessoas vulneráveis, não acostumadas a essas circunstâncias. Já uma entrevista mais interativa pode não ser a melhor opção quando a pesquisa envolve assuntos tabu ou experiências traumáticas, por exemplo. Para determinados perfis de entrevistados será viável a realização de diversos encontros, enquanto para outros isso pode ser um desafio.

Quanto à seleção dos entrevistados e à definição da quantidade de entrevistas, como é próprio da abordagem qualitativa, a utilização de técnicas de amostragem estatística não é indicada. Na pesquisa biográfica, o principal critério de seleção é que as pessoas tenham uma experiência potencialmente rica para compartilhar em relação ao assunto pesquisado (MERRIL; WEST, 2009). Ao invés de critérios quantitativos de verificabilidade e universalidade, as escolhas devem basear-se naquilo que vincula as trajetórias das pessoas entrevistadas ao objetivo da pesquisa, bem como ao procedimento de saturação qualitativa, a partir da análise das informações, para estabelecer o fim do esforço de coleta (MAGESTE; LOPES, 2007). A estratégia da bola de neve (quando um pesquisado indica uma ou mais pessoas com potencial de participar da pesquisa) é comumente utilizada (MERRIL; WEST, 2009) como meio de manter a coerência e diversidade dos entrevistados em relação as suas experiências. Na prática, selecionar os entrevistados trata-se de identificar aqueles que são considerados capazes de produção narrativa (HOLSTEIN, 1995), sem perder de vista que a definição dos entrevistados também está relacionada ao contexto de realização da pesquisa, o que envolve seu tempo de desenvolvimento, a quantidade de pesquisadores implicados e o orçamento de pesquisa disponível (MERRIL; WEST, 2009).

Quanto às questões éticas, o contato com experiências, perspectivas e sentimentos pessoais podem trazem implicações morais que afetam tanto o papel do pesquisador, quanto o uso das informações coletadas. É dever do entrevistador proteger as informações do entrevistado, considerando seus interesses, direitos e privacidade. Dentro do protocolo ético a ser adotado no planejamento de pesquisa é preciso que tudo seja posto de forma clara ao entrevistado desde o início sobre os objetivos e a agenda do entrevistador para que ele possa saber exatamente o que se planeja fazer com suas histórias. O pesquisador deve estar aberto a negociações, preservando, se necessário, o anonimato do entrevistado e respeitando seu eventual desejo de interromper sua colaboração com a pesquisa (ATKINSON, 1998). Além disso, se alguma situação de poder colocar o entrevistado em uma posição vulnerável, isso pode afetar não apenas a voz em que a história é contada, mas também o impacto que a narrativa tem 
sobre quem a faz (ATKINSON, 2002). O poder também se apresenta quando o pesquisador define a quem confere voz e a quem cala (HOLSTEIN, 1995), definindo que experiências ou subjetividades são válidas para o estudo. Essas tensões devem ser levadas em conta pelos pesquisadores no momento de planejar sua ação de pesquisa, de modo a identificá-las e considerar seu impacto ao longo do desenvolvimento da pesquisa.

\subsubsection{Processo de entrevista}

Durante a interação com o entrevistado, aparecem surpresas e questões que precisam ser levadas em consideração pelo pesquisador.

Como criar confiança e se mostrar um bom ouvinte? A introdução da pesquisa e de seus procedimentos com clareza e organização fornece uma base sólida para o trabalho biográfico (MERRILL; WEST, 2009). Uma escuta atenta e interessada ajuda a criar um laço de confiança com o entrevistado, permitindo o acesso a uma gama mais íntima, detalhada e rica de informações. Uma escuta ativa pode ser demonstrada com contato visual e sons não verbais que indiquem que você está ouvindo (WENGRAF, 2001). A escuta ativa também vem com uma observação aguçada da maneira como o entrevistado fala, o uso da linguagem corporal, expressões emocionais, sentimentos, etc. Por meio dessa competência, o pesquisador pode buscar acessar conteúdos mentais, intelectuais, cognitivos e emocionais do entrevistado (KIM, 2016). Permita ao entrevistado o acontecimento de pausas e silêncios. Esta conduta pode estimular o entrevistado a avançar em seu relato, demonstrando uma escuta interessada e ativa do pesquisador que não está apenas ali coletando dados, mas está fazendo da entrevista em um ato reflexivo (ATKINSON, 1998) no qual entrevistado e entrevistador criam sentidos.

Como estimular que as respostas sejam formuladas como histórias? Numa entrevista biográfica, as respostas devem se constituir um relato de experiências. Mais importante que perguntar “por que?" e "para quê?" é estimular o entrevistado perguntando: “como isso ou aquilo aconteceu?" ou “o que aconteceu na sequência?’. As razões, motivações e emoções devem emergir da história narrada na medida em que expõem problemas e possibilidades que não são visíveis quando a atenção é restrita às trocas de perguntas e respostas (MISHLER, 1986). Contar histórias está longe de ser incomum, mas é preciso que o entrevistado tenha espaço para falar. O pesquisador deve se manter em segundo plano, demonstrando atenção e interesse, assim como evitando juízos de valor quanto ao que está sendo exposto. Regras de conversação como pausas, divagações, alternância de fala, retomada de algum ponto específico, 
esclarecimentos ou reforços necessários, etc. - oportunizam um verdadeiro diálogo entre entrevistado e entrevistador, sem perder de vista a centralidade da voz do entrevistado. No caso da necessidade de uma intervenção verbal, cabe aproveitar as próprias palavras do entrevistado, estimulando-o a avançar no seu relato sem interferências excessivas (WENGRAF, 2001). Mais que estimular os relatos a partir da memória, os entrevistadores podem assumir que os participantes serão capazes de reconstruir sua experiência (SEIDMAN, 2019).

Como acolher a história da forma que ela se apresenta? Os relatos podem apresentar feições variadas tanto de um entrevistado para outro, quanto em momentos distintos do mesmo entrevistado. Eles podem ser mais ricos (estrutura mais definida com personagens, encadeamento temporal e motivações mais claras, além de foco maior na ação) ou mais fragmentados (múltiplos desdobramentos, vozes em um fluxo de consciência cujo sentido ainda está em gestação) (MUSSON, 1998). É preciso manter-se receptivo em ambas as situações, já que a própria forma do relato carrega em si informações e insights valiosos no processo de pesquisa. Técnicas de associação livre, derivadas de ideias psicoterapêuticas, podem ser incentivadas, valorizando a expressão ainda que não haja uma relação lógica ou racional entre o tópico em questão e o que o entrevistado está dizendo. As pessoas podem ser solicitadas a dizer o que lhes vem à mente, o que pode abrir áreas ricas de conexão e investigação (MERRIL; WEST, 2009). Além disso, se emoções fortes surgirem durante a entrevista (ATKINSON, 1998), o pesquisador poderá espelhá-los, dando ao entrevistado a sensação de aceitação destas emoções e que elas contribuem para o processo de pesquisa. Uma postura empática e não intrusiva é uma habilidade importante a ser adquirida (WENGRAF, 2001) e que pode levar o pesquisador a acessar informações em profundidade.

Como alternar entre guiar e ser guiado? O entrevistador de histórias de vida é uma espécie de guia para a jornada em que entrevistador e entrevistado estão embarcando. Interferir no momento certo e da maneira certa pode resultar na abertura de ricas veredas. Um bom guia está à procura de sinais que indiquem quando avançar e quando recuar. É necessário sensibilidade para saber a hora de mudar de papel e se deixar ser guiado pelo entrevistado, sendo flexível e permitindo que a pessoa se expresse ou mesmo perseguindo tópicos novos e interessantes (ATKINSON, 1998). É comum que o pesquisador busque ser mais direto na busca de seus objetivos de pesquisa, desprezando os elementos contextuais e emocionais (CZARNIAWSKA, 2002). Mas é preciso entender que a entrevista biográfica se baseia em uma relação profunda de troca (ATKINSON, 2012). 


\subsection{PROCEDIMENTOS ANALÍTICOS: ANÁLISE DE NARRATIVAS}

A etapa de análise pode ser dividida em dois momentos: a transcrição e a interpretação. O propósito da transcrição é transformar o tempo de entrevistas gravadas (documento primário) em uma narrativa legível (documento secundário). A tarefa do pesquisador ao transcrever uma entrevista biográfica é contar a história da pessoa com as palavras que ela usou. Trata-se de uma tarefa árdua e demorada que pode assumir diferentes características a depender dos propósitos da pesquisa. Há aquelas que demandam transcrições completas, outras que aceitam transcrições menos detalhadas. Já outras apresentam a transcrição ao entrevistado para que a examine e, eventualmente, a revise. Em seu tempo, a etapa de interpretação consiste em um processo de construção de significado a partir do material coletado em articulação com a base teórica estudada. Estabelecer significado e validade às histórias coletadas depende de alguns fatores: (a) qualidade do relacionamento que o pesquisador tem com o entrevistado, (b) o tipo de interação que existiu durante a entrevista, (c) a perspectiva teórica adotada e (d) a própria subjetividade do pesquisador (ATKINSON, 1998).

Cada disciplina, dentro de suas tradições de pesquisa, tem seu próprio ponto de partida para analisar as histórias de vida, mesmo que o ponto chave seja reconhecer como a estrutura da história e seus elementos (enredo, resolução inicial de confusão, personagens e seus papéis) se encaixam e criam um todo interativo entre si (ATKINSON, 1998). O carácter interpretativo, dialógico e contextual das narrativas são características preponderantes no processo de interpretação do material empírico. Nesse sentido, é útil ao pesquisador se acercar a um vocabulário analítico que lhe possibilite começar a enxergar o mecanismo que compõe as histórias de vida, o que pode se dar a partir de diferentes perspectivas. Do ponto de vista das dimensões das narrativas as histórias de vida apresentam alguns ou todos os componentes do discurso: descrição, cronologia, avaliação e explicação (OCHS, 2001). Os cenários são criados a partir de descrições. Os enredos apresentam uma cronologia linear ou mais complexa de eventos, fornecendo uma explicação do porquê um evento ocorreu em um ponto específico da sequência narrativa. Desde o início, a história é imbuída de uma avaliação moral e estética de ações, emoções, pensamentos e condições mundanas.

Do ponto de vista do trabalho narrativo, ou seja, do processo de geração de sentido, podem-se identificar nas histórias de vida os seguintes mecanismos: ativação, ligação, composição, performance, colaboração e controle (GUBRIUM; HOLSTEIN, 2009). A ativação corresponde aos mecanismos interacionais que colocam a narrativa em marcha, tais 
como as interações entre pesquisador e entrevistado e as circunstâncias nas quais as narrativas são produzidas. A ligação corresponde aos mecanismos de conexão entre eventos ou experiências relatadas criando um contexto particular dotado de um sentido próprio. A composição corresponde aos temas e tramas escolhidos pelo entrevistado para compor a história. A performance corresponde aos mecanismos de mediação cênica das histórias, seus detalhes performativos, papéis, propósitos, audiências, modos de expressão e ênfases. A colaboração diz respeito a como os parceiros de conversação colaboram na produção das histórias e na construção de seus sentidos. Por fim, o controle corresponde às relações de poder que se estabelecem durante a produção narrativa determinando o que é dito e o que não é.

Um novo vocabulário analítico pode ser encontrado se as histórias forem tomadas a partir dos ambientes narrativos. Essas são forças sociais que influenciam as identidades dos participantes, o curso das ações, seus relacionamentos e, consequentemente, suas histórias de vida. Mais que espaços físicos, estes ambientes correspondem as diferentes escalas de relações sociais, tais como: relações próximas (ambientes familiares e relações íntimas); cultura local (ambientes de convivência da vida pública); o status (ambientes sociais definidos por critérios como a raça, gênero, classe social); profissão (formação e atuação profissional); organizações (espaços de atuação diversos em que os entrevistados se insiram como clubes, igrejas, agremiações, partidos políticos, etc.) e, por fim, intertextualidade (sobreposições e intercruzamento entre esses diferentes ambientes) (GUBRIUM; HOLSTEIN, 2009).

Um novo vocabulário analítico pode ser extraído a partir da observação da posição que o narrador ocupa no processo. Aplicando conceitos da narratologia aos Estudos Organizacionais, Hatch (1996) destaca dois conceitos: perspectiva narrativa e voz narrativa. A perspectiva narrativa corresponde à relação entre o narrador e a história, indicando se ela é contada de um ponto de vista interno ou externo. Já a voz narrativa descreve a relação entre o narrador e o ato narrativo, identificando se o narrador é ou não um personagem da história. Com base nestes conceitos, o narrador pode de ocupar quatro posições distintas: observador objetivo; personagem secundário; personagem principal e narrador onisciente.

Muitas são as vertentes analíticas possíveis para a análise de narrativas, elas variam amplamente entre si e devem ser adotadas pelos pesquisadores em estrito alinhamento com as características da investigação em curso. Alguns exemplos dessas vertentes incluem: análise narrativa temática, análise narrativa estrutural, análise narrativa dialógico-performativa, análise de narrativas sócio interacional e análise narrativa visual. 
A análise narrativa temática se centra no "que" está sendo dito (ou escrito). O foco da análise está mais naquilo que foi dito que na maneira de dizê-lo. As informações são interpretadas à luz do desenvolvimento temático do investigador (influenciado pelas teorias tomadas a priori ou que emergem na pesquisa, pela proposta de investigação, pelos dados em si, por comprometimentos políticos, etc.) (MAITLIS, 2012). Há pouca atenção ao contexto, às estruturas de discurso escolhidas pelo narrador, a quem o discurso está destinado ou a complexidade da transcrição. A análise narrativa temática é mais próxima aos métodos qualitativos como a grounded theory, a análise interpretativa fenomenológica, a história oral e ao folclore (RIESSMAN, 2008).

$\mathrm{Na}$ análise narrativa estrutural, o foco recai em como o narrador consegue persuadir o ouvinte que algo de fato aconteceu ou como as narrativas são estruturadas para alcançar seu objetivo. O interesse se desloca para o "como", ainda que, como a tipologia anterior, esta análise esteja concentrada no conteúdo do que é dito. A tradição que orienta esta análise é a narratológica e linguística de base estruturalista, que parte do princípio de que as histórias são estruturadas em seis componentes básicos: resumo (ponto principal da história), orientação (atores, tempo, local e situação), complicação (sequência de eventos), avaliação (significado da narrativa), resolução (resultado) e coda (final e retorno ao tempo presente) (MAITLIS, 2012). Vincula-se também às tradições de disciplinas como teoria literária, semiótica e retórica (CZARNIAWSKA, 2004). Relaciona-se com características que definem os gêneros e as estratégias de estruturação das histórias, podendo gerar um conhecimento que reforça a temática de análise do pesquisador, mas também pode abrir direções inesperadas para a pesquisa. Ela não é adequada para grandes amostras, mas pode ser muito útil para casos de estudo bem detalhados e comparação entre poucos casos. A microanálise que emana da análise narrativa estrutural pode ajudar o pesquisador (a) na construção de teorias que relacionam linguagem e sentido, (b) no entendimento de como os narradores usam o discurso para construir si próprios e suas histórias, e (c) na estruturação da tarefa de convencer e persuadir (RIESSMAN, 2008).

A análise narrativa dialógico-performativa é aquela que examina como a conversa entre falantes é interativamente produzida e performada como narrativa. O pesquisador é uma presença ativa e visível na coleta de informações, análise e escrita do relatório. Como o contexto interfere na contação da história e como a história é produzida em um contexto coreográficos (em espaços entre o narrador e o ouvinte, o cenário, a história e a cultura são preocupações deste tipo de análise. Enfatiza-se a importância da interação e o caráter performativo dessa interação, visto que, ainda que a linguagem seja uma via privilegiada de criação das histórias, 
o corpo e outras vias alternativas de comunicação contribuem significativamente para a construção dos discursos (RIESSMAN, 2008). Incorpora-se elementos temáticos e estruturais, mas acrescenta-se a preocupação sobre como as narrativas são co-construídas entre o entrevistado e o pesquisador, enfatizando a característica interacional e contextual da produção das histórias e da construção de seus sentidos (MAITLIS, 2012).

A análise de narrativas sociointeracional pode ser realizada em uma perspectiva em que narrativas são consideradas como práticas, como fala-em-interação, opondo-se a tradições mais debitarias de conceitos estruturalistas (FINA; GEORGAKOPOULOU, 2008). Esta perspectiva sociointeracionista parte do princípio que a narrativa não pode ser descolada de seu contexto de produção. O que é dito e como é dito está intimamente ligado ao contexto, caracterizando a narrativa como uma prática social e não como um ato autônomo e cujo sentido se encerra em si mesmo. Mais uma vez, a interação entrevistado e pesquisador, bem como a interação com o contexto social em que essa interação está imersa, são elementos fundamentais para o processo de análise.

A análise narrativa visual trata de uma fronteira emergente da interpretação da pesquisa narrativa, na qual as imagens constituem na principal informação a ser interpretada lado-a-lado às palavras dos criadores dessas imagens. Os dados podem ser imagens encontradas (fotografias, pinturas e desenhos) ou imagens feitas durante a pesquisa (autorretratos, vídeo diários, etc.). Examinados conjuntamente com textos falados ou escritos, são informações úteis para estudar a construção, solidificação ou ficcionalização de identidades (RIESSMAN, 2008)

Importante lembrar que as histórias de vida não são a finalidade das pesquisas desenvolvidas por meio dos métodos biográficos, mas constituem meios para que os objetivos de pesquisa sejam alcançados. A investigação narrativa mobiliza as histórias como energia para entender, analisar, avaliar e teorizar os fenômenos humanos e sociais. Assim sendo, é trabalho do pesquisador discutir e teorizar os resultados da pesquisa no contexto da disciplina na qual desenvolve o estudo. Cabe ao pesquisador desenvolver contribuição específica e implicações para seu campo de pesquisa com base nos referenciais teóricos adotados. Só assim, além de uma justificativa pessoal, a pesquisa ganhará valor prático, social e acadêmico (KIM 2016).

\section{DISCUSSÃO: DESAFIOS E IMPLICAÇÕES}


Muitos são os desafios que se colocam no caminho dos pesquisadores que aderem aos métodos biográficos. Conferimos destaque a três deles: o desafio de teorizar, de focar e de respeitar questões éticas.

Desafio de teorizar. $\mathrm{O}$ enfoque na história de vida pode encantar o pesquisador e tornar difícil um processo de interação e análise das narrativas de forma a gerar um conhecimento conceitual-teórico que represente uma contribuição efetiva para seu campo disciplinar. A entrevista da história de vida é altamente contextualizada, abordagem altamente personalizada para a coleta de informações qualitativas sobre a experiência humana. Trata-se da busca de articular uma voz com experiências únicas a uma experiência humana universal, fundamentando-se na experiência e na interpretação, dois termos muito relativos (ATKINSON, 2002). Assim sendo, enviesamento (CUNHA et al., 2017) e dificuldades em generalizações (ROULEAU, 2015) são desafios que via de regra se apresentam na utilização destes métodos. São desafios que nascem do princípio construtivista, interacionista, interpretativos e situacional dos métodos em contraste com a problematização, indevida, mas ainda vigente, quanto à validade científica da oralidade (ROULEAU, 2015) e da própria abordagem qualitativa. Em uma primeira instância este desafio se apresenta logo na escolha dos indivíduos cujas histórias serão pesquisadas de modo que possa se estabelecer uma dinâmica adequada entre história individual e o aspecto coletivo. Apesar da justificativa acadêmica (motivo pelo qual a pesquisa contribui para o avanço do conhecimento disciplinar) ser determinante, outras razões podem ser destacadas: pessoal (explicação de por que o estudo é relevante e por que é importante para o pesquisador), prática (explicação de como o estudo informará sobre suas práticas e as práticas de outras pessoas) e social (explicação de como o estudo pode abordar questões sociais maiores) (KIM, 2016).

Desafio de focar. De um ponto de vista micro, Roleau (2015) destaca desafios de ordem procedimentais quanto à aplicação dos métodos biográficos, no que concerne a manter o foco. Em primeira instância, este desafio se apresenta na interação com o material empírico, quando o pesquisador necessita manter a vigilância para manter o foco do entrevistado no relato das experiências que são efetivamente úteis para o alcance do objetivo da pesquisa. Contudo, isso deve ser feito sem ferir a dinâmica própria do fluxo imaginativo e memorial inerente a estes métodos. Em segunda instância, este desafio se apresenta também durante o processo de análise dos dados, tendo em vista que a abundância de informações, demanda do pesquisador o foco no objetivo de pesquisa. 
Desafio de respeitar a ética. Nos métodos biográficos, a questão ética não é simplesmente obter o consentimento do entrevistado para que sua história seja registrada e analisada, nem somente garantir a confidencialidade e anonimato. A análise narrativa implica extensos compromissos éticos, tendo em vista que o pesquisador que solicita as histórias das pessoas não coleta apenas dados, mas concorda em entrar em um relacionamento com o entrevistado e se tornar parte sua história (FRANK, 2002). Ao contar sua história de vida, uma pessoa se expõe e se apresenta vulnerável de muitas formas distintas (CASSELL et al., 2018), por isso é preciso não perder de vista que existe uma relação de poder entre entrevistador e entrevistado que pode afetar não apenas como a história é contada, mas o impacto do que é dito sobre quem está dizendo (ATKINSON, 2002). A ética também está relacionada ao processo de interpretação das histórias. Ainda que se trate de um método de natureza interpretativa, é necessário um compromisso para que inferências e deduções do pesquisador não deturpem a história de vida contata (CASSELL et al., 2018).

\section{CONCLUSÕES}

O objetivo que motivou esta pesquisa foi o de integrar conhecimentos sobre a aplicação dos métodos biográficos na pesquisa em Administração. Essa motivação decorre de uma revisão sistemática realizada em produções acadêmicas nacionais e internacionais que apresenta como resultado uma dispersão e fragmentação do conhecimento sobre os métodos biográficos. Os resultados da pesquisa repousam sobre o desenvolvimento de algumas categorias integradoras - princípios, potencialidades, práticas e desafios - a partir das quais buscou-se oferecer contribuições a pesquisadores interessados na utilização dos métodos biográficos uma melhor compreensão sobre seus fundamentos, práticas e procedimentos.

Como implicação deste estudo, espera-se promover um maior e melhor conhecimento sobre os métodos biográficos, estimulando sua maior adoção no campo da Administração, bem como possibilitando que sua aplicação seja feita com maior capacidade reflexiva e perícia. Dada à qualidade autorreflexiva própria dos métodos biográficos, espera-se ainda que seu uso consciente nas pesquisas em Administração promova contribuições sócio práticas. Com efeito, sabemos que o próprio engajamento em uma pesquisa biográfica pode estimular processos de tomada de consciência, criação de sentido e autorreflexão por parte de gestores entrevistados quanto a suas práticas e processos de gestão. Estimula-se, assim, um profícuo e necessário entrelaçamento entre pesquisa acadêmica e impacto social. 


\section{REFERÊNCIAS}

ALBERTI, V. Indivíduo e biografia na história oral. Rio de Janeiro: CPDOC, 2000.

ALBERTI, V. Tratamento das entrevistas de história oral no CPDOC. Rio de Janeiro: CPDOC, 2005.

ATKINSON, R. The Life Story Interview as a mutually equitable relationship. In: GUBRIUM, J. F.; HOLSTEIN, J. A.; MARVASTI, A. B.; MACKINNEY, K. D. (Eds.), Handbook of Interview Research. Thousand Oaks: Sage Publications SAGE, 2012, p. 115128.

ATKINSON, R. The Life Story Interview. In: GUBRIUM, J. F.; HOLSTEIN, J. A. (Eds.), Handbook of Interview Research. Thousand Oaks: SAGE, 2002, p. 121-140.

ATKINSON, R. The Life Story Interview. Thousand Oaks: Sage Publications, 1998.

BOJE, D. M. The Storytelling organization: a study of story performance in an office-supply firm. Administrative Science Quarterly, v.36, n.1, p. 106-126, 1991.

BOM MEIHY, J. C. S. Manual de história oral. São Paulo: Edições Loyola, 1996.

BOURDIEU, P. A ilusão biográfica. In: FERREIRA, M. M.; AMADO, J. (Eds.), Usos e abusos da história oral, Rio de Janeiro: Editora FGV, 2009, p. 183-192.

BUENO, B. O. O método autobiográfico e os estudos com Histórias de vida de professores: a questão da subjetividade. Educação e Pesquisa, v. 28, n.1, p. 11-30, 2012.

CAPPELLE, M. C. A; BORGES, C. L. P.; MIRANDA, A. R. A. Exemplo de Uso da História Oral como Temática Complementar de Pesquisa em Administração. In: ANPAD. Anais do VI Encontro de Estudos Organizacionais, Florianópolis, 2011.

CARVALHO, R. O. C.; FISCHER, T. M. Ars Antiqua: Mosteiro de São Bento, o Eterno no Tempo. Revista de Administração de Empresas, v.46, n.1, p. 14-26, 2016.

CASSELL, C.; CUNLIFFE, A. L.; GRANDY, G. Qualitative Research in Business and Management. In: CASSELL, C.; CUNLIFFE, A. L.; GRANDY, G. Handbook of Qualitative Business and Management Research Methods. Thousand Oaks: SAGE, 2018, p. 1-14.

COLOMBY, R. K.; PERES, A. L.; TARABAL, F. L.; COSTA, S. G. Histórias de Vida como um caminho metodológico em estudos organizacionais: um estudo bibliométrico. In: IV Congresso Brasileiro de Estudos Organizacionais. Porto Alegre, 2016. 
CORRÊA, A. M. H.; CARRIERI, A. P. Percurso Semântico do Assédio Moral na Trajetória Profissional de Mulheres Gerentes. Revista de Administração de Empresas, v.47, n.1, p. 22-32, 2007.

CUNHA, M. P.; LEWIS, M. W.; REGO, A.; SMITH, W. K. Biographical methods in leadership research. In: SCHYNS, B.; HALL, R. J.; NEVES, P. Handbook of Methods in Leadership Research. Cheltenham: Edward Elgar Publishing, 2017, p. 372-400.

CZARNIAWSKA, B. Narrating the Organization: Dramas in Institutional Identity. Chicago: University of Chicago Press, 1997.

CZARNIAWSKA, B. Narrative, interviews, and organizations. In: GUBRIUM, J. F.; HOLSTEIN, J. A. (Eds.). Handbook of Interview Research: Context \& Method. Thousand Oaks: Sage Publications, 2002, p. 733-749.

CZARNIAWSKA, B. Narratives in social science research. London: Sage Publications, 2004.

DENIS, J. L.; LANGLEY, A.; ROULEAU, L. The practice of leadership in the messy world of organizations. Leadership, v.6, n.1, p. 67-88, 2010.

FERREIRA, M. M.; AMADO, J. Usos e abusos da história oral. Rio de Janeiro: Editora FGV, 2009.

FINA, A. D.; GEORGAKOPOULOU, A. Analysing narratives as practices. Qualitative Research, v.8, n.3, p. 379-387, 2008.

FRANÇOIS, E. A fecundidade da história oral. In: FERREIRA, M.; AMADO, J. Usos e abusos da história oral. Rio de Janeiro: Editora da Fundação Getúlio, 2009, p. 3-13.

FRANK, W. F. Why Study People's Stories? The Dialogical Ethics of Narrative Analysis. International Journal of Qualitative Methods, v.1, n.1, p. 109-117, 2002.

FRÉMEUX, S.; PAVAGEAU, B. Meaningful Leadership: How Can Leaders Contribute to Meaningful Work? Journal of Management Inquiry, v.13, n.1, p. 1-13, 2020.

GUBRIUM, J. F; HOLSTEIN, J. A.; MARVASTI, A. B.; MACKINNEY, K. D. Handbook of Interview Research. Thousand Oaks: Sage Publications, 2012.

GUBRIUM, J. F.; HOLSTEIN, J. A. Analyzing narrative reality. Thousand Oaks: Sage Publications, 2009.

HATCH, M. J. The role of the researcher: an analysis of narrative position in organization theory. Journal of Management Inquiry, v.5, n.4, p. 359-374, 1996.

HOLSTEIN, J. A.; GUBRIUM, J. F. The active interview. Thousand Oaks: Sage Publications, 1995.

HOLSTEIN, J. A.; GUBRIUM, J. F. Varieties of narrative analysis. Los Angeles: Sage Publications, 2012. 
ICHIKAWA, E.Y.; SANTOS, L.W. (2003, setembro). Vozes da história: contribuições da história oral à pesquisa organizacional. Trabalho apresentado no Encontro da Associação Nacional de Pós graduação e pesquisa em Administração - EnANPAD, Atibaia, Brasil, 2003.

KIM, J. H. Understanding Narrative Inquiry: The Crafting and Analysis of Stories as Research. Los Angeles: Sage Publications, 2016.

LAMBRIGHT, W. H.; QUINN, M. M. Understanding leadership in public administration: the biographical approach. Public Administration Review, v.71, n.5, p. 782-90, 2011.

LEVI, G. Usos da biografia. In: FERREIRA, M. M.; AMADO, J. FERREIRA, M. M. \& AMADO, J., Usos e abusos da história oral. Rio de Janeiro: Editora FGV, 2009.

LIČEN, N.; CIIUHA, S. Learning in Everyday life: towards a new method of researching the field. Facta Universitatis, v.11, n.1, p. 55-66, 2012.

LIEBLICH, A. (2013). Healing plots: writing and reading in life-stories groups. Qualitative Inquiry, vol.19, n. (1), p. 46-52.

LOZANO, J. Prática e estilos de pesquisa na história oral contemporânea. In: FERREIRA, M. M.; AMADO, J., Usos e abusos da história oral. Rio de Janeiro: Editora FGV, 2009.

MAGESTE, G. S.; LOPES, F. T. O Uso da História de Vida nos Estudos Organizacionais. In: I Encontro de Ensino e Pesquisa em Administração e Contabilidade, Recife, 2007.

MAITLIS, S. Narrative analysis. In: SYMON, G.; CASSELL, C. (Ed.). Qualitative organizational research: core methods and current challenges. Los Angeles: Sage Publications, 2012.

MERRILL, B.; WEST, L. Using Biographical Methods in Social Research. London: Sage Publications, 2009.

MISHLER, E. C. Research Interviewing Context and Narrative. Cambridge: Harvard University Press, 1986.

MUSSON, G. Life histories. In: SYMON, G.; CASSELL, C. (Ed.). Qualitative methods and analysis in organizational research. London: Sage Publications, 1998, p. 10-27.

OCHS, E.; CAPPS, L. Living narrative: creating lives in everyday storytelling. Cambridge: Harvard University Press, 2001.

RIESSMAN, C. K. Narrative analysis. Newbury Park: Sage PublicationsSage, 1993.

RIESSMAN, C. K. Narrative Methods for the human sciences. Los Angeles: Sage Publications, 2008.

ROBERTS, B. Biographical research. Buckingham: Open University Press, 2002. 
ROULEAU, L. Studying strategizing through biographical methods: narratives of practices and life trajectories of practitioners. In: GOLSORKHI, D.; ROULEAU, L.; SEIDL, D.;

VAARA, E. Handbook of Strategy as Practice. Cambridge: Cambridge University Press, 2015, p. 462-476.

ROULEAU, L.; BALOGUN, J. Middle Managers, Strategic Sensemaking, and Discursive Competence. Journal of Management Studies, v.48, n.5. p. 953-983, 2011.

SEIDMAN, I. Interviewing as qualitative research: a guide for researchers in education and the social sciences. New York: Teachers College Press, 2019.

TSOUKAS, H.; HATCH, M. J. Complex thinking, complex practice: the case for a narrative approach to organizational complexity. Human Relations, v.54, n.8, p. 979-1013, 2001.

WATSON, T. J. Narrative, life story and manager identity: A case study in autobiographical identity work. Human Relations, v.62, n.3, p. 425-452, 2009.

WENGRAF, T. Qualitative research interviewing: biographic narrative and semistructured methods. London: Sage Publications, 2001. 